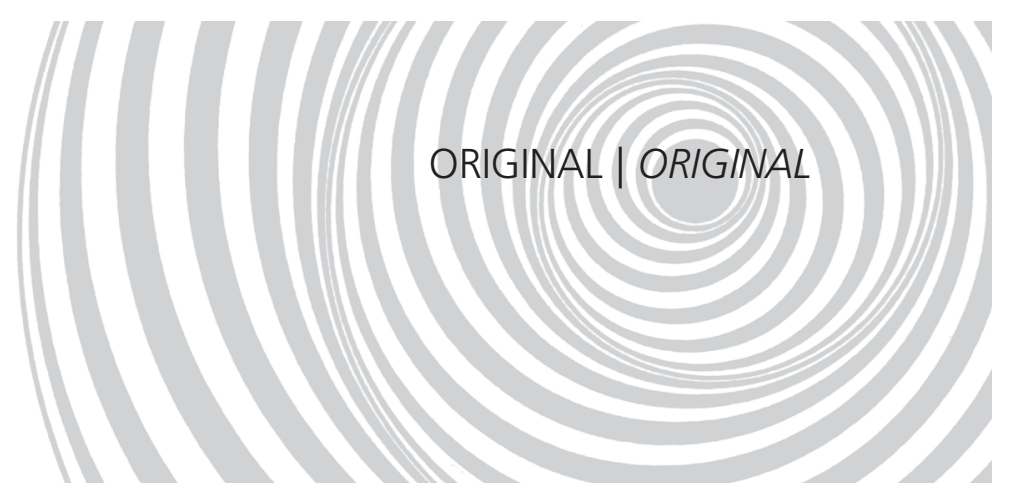

\title{
Caracterização química do autolisado de levedura de alambique e avaliação da aceitabilidade do pão de queijo adicionado do autolisado desidratado ${ }^{1}$
}

\author{
Chemical characterization of yeast autolysate \\ and assessment of the acceptability of cheese \\ buns containing dried autolysate
}

Giselle Rossi Vasconcelos RAMOS²

Viviane Santos BIRCHAL ${ }^{3}$

Luciana Moreira SEARA²

Felipe Duarte PEREIRA ${ }^{4}$

Patrícia ALVISI ${ }^{4}$

RE S U M O

\section{Objetivo}

Esta pesquisa tem como objetivo estudar as propriedades do autolisado de levedura (Saccharomyces cerevisiae) proveniente de cachaça de alambique, investigando a composição centesimal, o perfil acídico e a análise microbiológica do material, bem como realizar análise sensorial do pão de queijo adicionado com o autolisado desidratado.

\section{Métodos}

O autolisado foi obtido pela lavagem e autólise da biomassa. A secagem foi realizada em secador de bandeja na temperatura de $70^{\circ} \mathrm{C}$. Realizaram-se as seguintes análises: caracterização físico-química (teor lipídico, proteico, fibras totais, fibras solúveis e insolúveis, e cinzas); composição de aminoácidos; análises microbiológicas do produto desidratado; e avaliação sensorial do pão de queijo contendo o autolisado desidratado, através de escala hedônica e teste de atitude.

1 Artigo elaborado a partir da dissertação de G.R.V. RAMOS, intitulada "Obtenção, caracterização e secagem do autolisado de levedura (Saccharomyces cerevisiae) de alambique". Centro Universitário de Belo Horizonte; 2009.

2 Centro Universitário de Belo Horizonte, Programa de Mestrado Profissional em Tecnologia de Alimentos. Av. Prof. Mário Werneck, 1685, Estoril, 30455-610, Belo Horizonte, MG, Brasil. Correspondência para/Correspondence to: G.R.V. RAMOS:

E-mail:<girossinutri@yahoo.com.br>.

3 Universidade Federal de Minas Gerais, Escola de Engenharia, Departamento de Engenharia Química. Belo Horizonte, MG, Brasil.

${ }^{4}$ Centro Universitário de Belo Horizonte, Curso de Engenharia de Alimentos. Belo Horizonte, MG, Brasil. 
474 | G.R.V. RAMOS et al.

\section{Resultados}

O autolisado desidratado apresentou: 1,2\% de lipídeos; $24,7 \%$ de proteínas; $51,3 \%$ de fibras totais, sendo $2,4 \%$ de fibras solúveis e 48,9\% de insolúveis; e 6,2\% de cinzas. As análises microbiológicas mostraram-se dentro do limite recomendado pela Agência Nacional de Vigilância Sanitária. O perfil aminoacídico mostrou deficiência de histidina e metionina+cistina. A análise sensorial do pão de queijo mostrou boa aceitação, tendo apenas cor e aparência recebido notas baixas. A maioria dos participantes disse que "gosta disto e compraria de vez em quando".

\section{Conclusão}

Os valores de proteína e aminoácidos encontrados na levedura de cachaça de alambique foram inferiores ao mostrado na literatura para levedura de cervejaria e destilaria de álcool etílico. A levedura desidratada estava microbiologicamente apta para consumo humano. A baixa aceitabilidade da aparência do pão de queijo provavelmente ocorreu pelo fato de os consumidores não estarem habituados à cor escura do produto. Trabalhos futuros poderão sugerir adição em outros produtos que apresentem aparência mais atrativa.

Termos de indexação: Autólise. Leveduras. Pão. Saccharomyces cerevisiae.

\section{A B S T R A C T}

\section{Objective}

This study aimed to study the properties of yeast (Saccharomyces cerevisiae) autolysate obtained from pot still rum, including centesimal composition, amino acid profile and microbiological analysis, and perform a sensory analysis of cheese buns (also known as Brazilian cheese bread or rolls) enriched with dried autolysate.

\section{Methods}

Autolysate was obtained by rinsing and autolyzing the biomass and dried on a tray dryer at $70^{\circ}$. Its composition was then determined (fat, protein, total fiber, soluble fiber, insoluble fiber, ash and amino acid contents) followed by microbiological analysis. Finally, cheese buns enriched with dried autolysate were submitted to sensory analysis using the hedonic scale and attitude test.

\section{Results}

Dried autolysate contained $1.2 \%$ fats; $24.7 \%$ proteins; $51.3 \%$ total fiber, where $2.4 \%$ was soluble and $48.9 \%$ was insoluble; and $6.2 \%$ ash. According to microbiological analysis, the product complied with the microbiological limits established by the Agência Nacional de Vigilância Sanitária. Amino acid profile showed that histidine and methionine-cystine levels were low. Sensory analysis indicated good acceptance of the cheese buns. Only their color and appearance received low scores. Most participants reported liking the cheese buns and willingness to buy them on occasion.

\section{Conclusion}

The protein and amino acid levels found in pot still rum were lower than those reported in the literature for breweries and ethanol distilleries. Dried yeast was microbiologically suitable for human consumption. The low grades given to the appearance of the cheese buns were probably due to their unappealing dark color, as opposed to the usual pale yellow color. Future studies could suggest the addition of dried yeast to products whose visual appeal will not be as affected.

Indexing terms: Autolysis. Yeast. Bread. Saccharomyces cerevisiae.

\section{N T R O D U Ç Ã O}

A cachaça é uma bebida tipicamente brasileira, que vem se destacando no mercado internacional devido ao sabor e aroma especiais ${ }^{1}$. O processo de produção da cachaça de alambique consiste na adição de leveduras ativas, predominante- mente Saccharomyces cerevisiae, a uma mistura de caldo de cana e melaço, provocando a fermentação. Em seguida, o creme de levedura viva é separado do vinho, que segue para destilação, enquanto parte da levedura é novamente adicionada ao processo de fermentação, e a parte excedente é descartada². 
O Brasil produz aproximadamente 1,5 bilhões de litros de cachaça ao ano. Em 2008 o País exportou 11,09 milhões de litros, gerando uma receita de US\$16,41 milhões ${ }^{3}$. No mercado interno, o setor da cachaça gera mais de 600 mil empregos diretos e indiretos em todo o território nacional ${ }^{3}$.

Do total produzido, 400 milhões de litros são de cachaça artesanal4,5. Em Minas Gerais já foram registrados aproximadamente 8500 alambiques, responsáveis pela produção de cerca de 220 milhões de litros/ano ${ }^{4}$. Em 2009, o estado teve um aumento de $62 \%$ na exportação, com vendas de US\$696 mil, passando a ser o quinto maior exportador do País ${ }^{6}$.

O processo de produção de cachaça gera vários resíduos que são potenciais poluentes do meio ambiente, dentre os quais o excedente de levedura obtido na fermentação, que é descartado frequentemente de maneira inadequada, sem qualquer tratamento prévio. A geração de biomassa de levedura no setor sucroalcooleiro é de cerca de $20 \mathrm{~kg}$ a $30 \mathrm{~kg}$ de levedura por $1 \mathrm{mil} \mathrm{li-}$ tros de álcool produzido. Estima-se que na safra de 2013/14 a produção deverá ser de 28 miIhões///álcool aproximadamente, duplicando a produção desse resíduo 7,8 .

O excedente da levedura desprezada na fermentação alcoólica pode ser aproveitado na alimentação animal e humana, tanto de forma integral (célula ativa ou inativa), quanto em apenas alguns de seus componentes (produtos derivados da parede celular e também do conteúdo celular)². As células íntegras são usadas principalmente na alimentação animal, ao passo que certos derivados produzidos pela autólise das células, como o autolisado, podem ser adicionados a produtos alimentícios, como complemento nutritivo, aromatizante e realçador de sabor ${ }^{9}$. O extrato de levedura contém todo o material solúvel do autolisado, incluindo proteínas, peptídeos, aminoácidos livres, nucleotídeos, vitaminas, oligossacarídeos e minerais. A fração insolúvel, composta principalmente de parede celular é rica em manoproteínas, $\beta$ - glicana e manana ${ }^{10}$.
Nesse sentido, o presente trabalho tem como objetivos: determinar a composição centesimal do autolisado de levedura proveniente de cachaça de alambique; verificar o perfil de aminoácidos presentes; caracterizar o autolisado desidratado microbiologicamente; e desenvolver análise sensorial de pão de queijo com adição do autolisado desidratado. Ressalte-se que não foram encontrados na literatura valores referentes à caracterização de leveduras provenientes da fabricação de cachaça de alambique.

\section{M É T O D O S}

A suspensão de células de levedura (aproximadamente $30 \%$ de células) utilizada nos ensaios foi doada por uma indústria de cachaça artesanal da cidade de Belo Horizonte, Minas Gerais, Brasil.

A obtenção do autolisado de levedura foi realizada com base nos procedimentos descritos na literatura ${ }^{11,12}$, conforme esquematizado na Figura 1.

As células foram inicialmente lavadas em água e centrifugadas. O processo de lavagem foi realizado duas vezes, com o objetivo de eliminar as impurezas e o álcool remanescente. A biomassa limpa foi submetida a processo de autólise, para rompimento das paredes celulares. Para isso, foram adicionados à biomassa etanol $(7 \%), \mathrm{NaCl}$ (2\%) e pré-autolisado (15\%); o pH foi corrigido a $5,5 \mathrm{com} \mathrm{NaOH} 0,1 \mathrm{~N}$; e o composto foi levado à incubadora, para agitação e homogeneização. A autólise foi conduzida sob agitação, por 24 horas a $55^{\circ} \mathrm{C}$, e foi interrompida com pasteurização a $85^{\circ} \mathrm{C}$ por 15 minutos. Após a pasteurização, as amostras de levedura autolisada foram desidratadas em secador de bandeja convectivo (ar a $3 \mathrm{~m} / \mathrm{s}$ ) a $70^{\circ} \mathrm{C}$ (Figura 1).

A caracterização físico-química do produto desidratado foi realizada determinando-se: o teor de cinzas, por calcinação em mufla a $550^{\circ} \mathrm{C}^{13}$; os lipídeos foram determinados por meio do extrator de Soxhlet ${ }^{13}$; proteínas brutas, pelo método de Kjeldahl, com fator de conversão nitrogênio/proteína igual a $6,25^{13}$, os carboidratos foram deter- 


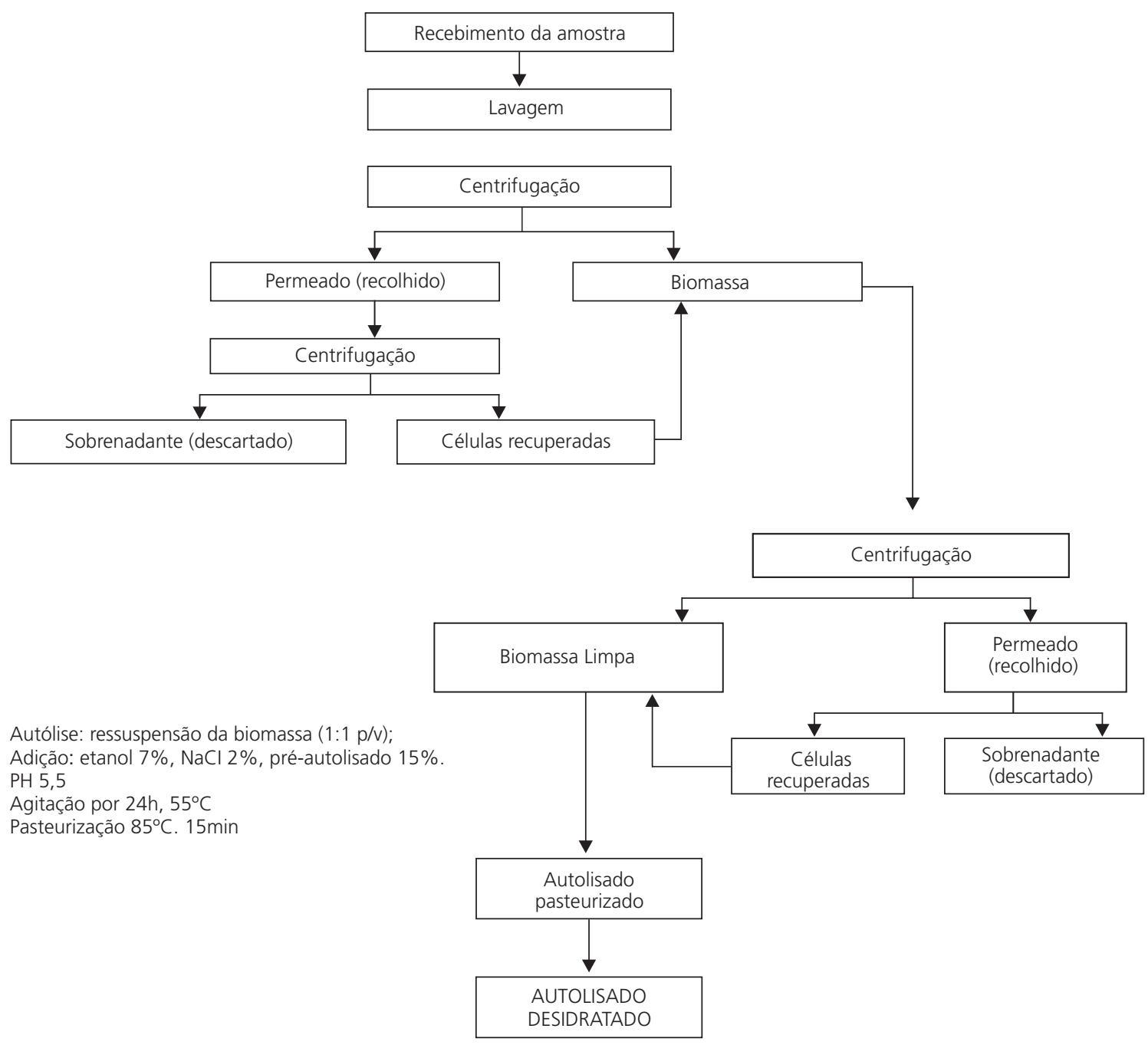

Figura 1. Fluxograma do processo de limpeza e autólise da biomassa de levedura (Saccharomyces cerevisiae). Belo Horizonte (MG), 2009.

minados pela diferença: $100 \%$ - (\% de água + teor de proteína + teor de lipídeos + cinzas), os valores de carboidratos incluem a fibra alimentar total; e os teores de fibra insolúvel e fibra solúvel, pela hidrólise enzimática ${ }^{14}$. O teor de umidade foi determinado por método gravimétrico, através da secagem da amostra a $105^{\circ} \mathrm{C}$ até peso constante em estufa ${ }^{13}$, foi realizado para a determinação do carboidrato. Todas as análises foram realizadas em triplicata, para a determinação do erro experimental.

A determinação da composição de aminoácidos foi feita pelo método cromatográfico
(HPLC), no laboratório de fontes proteicas da Faculdade de Engenharia de Alimentos (FEA) da Universidade Estadual de Campinas (Unicamp).

Para levedura desidratada a Agência Nacional de Vigilância Sanitária (ANVISA) recomenda análises microbiológicas para Salmonella sp. $/ 25 \mathrm{~g}$, para Coliformes a $45^{\circ} \mathrm{C} / \mathrm{g}$, para Estafilococos coagulase positiva/g e para Bacilus cereus/g ${ }^{15}$. As análises microbiológicas no autolisado de levedura desidratado foram feitas baseadas na Instrução Normativa $n^{\circ} 62$, de 26 de agosto de 2003, do Ministério da Agricultura ${ }^{16}$, tendo sido realizadas antes da formulação do pão de queijo. 


\section{Formulação do produto}

Por se tratar de um produto típico de Minas Gerais e com grande aceitação no mercado nacional, optou-se pela adição do autolisado de levedura desidratado a uma formulação de pão de queijo. Este foi preparado acrescentando-se ao polvilho uma mistura de leite, água, margarina e sal fervente, e, após, adicionando-se ovo, queijo e 7,5\% do autolisado de levedura (em relação à quantidade de polvilho), conforme formulação proposta na literatura ${ }^{17}$. Após o preparo, a massa foi dividida em esferas de $50 \mathrm{~g}$, assadas a $180^{\circ} \mathrm{C}$ por 25 minutos.

\section{Análise Sensorial}

A análise sensorial do pão de queijo adicionado do autolisado de levedura (Anexo) teve por objetivo analisar os atributos característicos do produto com aquela adição, quais sejam: aparência, cor, aroma, textura e sabor, além da intenção de compra, caso o produto estivesse disponível no mercado.

Os testes empregados para avaliar a aceitação e a intenção de consumo, através da escala hedônica e de atitude, foram baseados nas metodologias descritas na literatura e realizados no laboratório de análise sensorial do Uni-BH ${ }^{18}$.

Participaram da pesquisa 71 participantes, selecionados ao acaso no pátio do Centro Univer- sitário de Belo Horizonte (Uni-BH), independentemente de critérios de idade, sexo, raça ou renda.

O estudo foi aprovado pelo Comitê de Ética em Pesquisa do Centro Universitário de Belo Horizonte (Uni-BH), sob protocolo $n^{\circ}$ 077/2008, em 6 de março de 2009, tendo todos os participantes assinado o Termo de Consentimento livre e esclarecido antes de sua inclusão na amostra.

\section{RESULTADOS}

A Tabela 1 apresenta a composição centesimal do autolisado de levedura desidratado para cada componente, com seus valores médios, acompanhados do erro experimental. Para fins de comparação, a Tabela apresenta também os valores reportados na literatura para autolisado de leveduras provenientes de cervejaria e de destilaria de álcool etílico. A distribuição dos macronutrientes foi de $24,7 \%$ para proteína, 1,2\% para lipídeos e 63,1\% para carboidratos. O conteúdo de fibras totais foi de $51,3 \%$, sendo $2,4 \%$ de fibras solúveis e $48,9 \%$ de insolúveis. O teor de cinzas determinado foi de $6,2 \%$, e umidade de $4,8 \%$.

A Tabela 2 mostra a composição de aminoácidos essenciais da levedura de cachaça de alambique, apresentando os valores médios acompanhados do erro experimental, bem como valores obtidos na literatura e no padrão Organización Mundial de la Salud para adultos.

Tabela 1. Composição centesimal (\%) do autolisado de leveduras (Saccharomyces cerevisiae) provenientes de cachaça de alambique, cervejaria e destilaria de álcool etílico.

\begin{tabular}{|c|c|c|c|c|}
\hline \multirow{2}{*}{ Procedência/Componente } & \multicolumn{2}{|c|}{ Cachaça de alambique (\%) } & \multirow{2}{*}{$\frac{\text { Cervejaria }^{19}}{\%}$} & \multirow{2}{*}{$\frac{\text { Destilaria de álcool }{ }^{9}}{\%}$} \\
\hline & M & DP & & \\
\hline Proteína & 24,7 & 1,0 & 43,9 & 40,4 \\
\hline Lipídeos & 1,2 & 0,1 & 3,3 & 1,2 \\
\hline Carboidratos & 63,1 & 63,1 & - & - \\
\hline Fibras totais & 51,3 & 0,1 & 26,5 & 31,2 \\
\hline Fibras solúveis & 2,4 & 0,1 & 26,2 & 30,4 \\
\hline Fibras insolúveis & 48,9 & 0,1 & 0,3 & 1,0 \\
\hline Cinzas & 6,2 & 0,3 & 7,1 & 6,2 \\
\hline Umidade & 4,8 & 0,2 & - & - \\
\hline
\end{tabular}

M: média; DP: desvio-padrão. 
Tabela 2. Composição de aminoácidos essenciais da proteína de levedura proveniente de cachaça de alambique, comparada aos padrões de referência da literatura e da FAONHO ${ }^{19}$ (1985). Belo Horizonte (MG), 2009.

\begin{tabular}{|c|c|c|c|c|c|}
\hline \multirow{2}{*}{ Aminoácidos(g/100g proteína) } & \multicolumn{2}{|c|}{ Autolisado $^{a}$} & \multirow{2}{*}{ Literatura $^{11}$} & \multirow{2}{*}{ Literatura $^{11}$} & \multirow{2}{*}{$\begin{array}{c}\text { Padrão FAO WHO20 } \\
\text { (Adultos) }\end{array}$} \\
\hline & M & DP & & & \\
\hline Treonina & 1,41 & 0,01 & 5,84 & 5,2 & 0,7 \\
\hline Histidina & $0,46^{*}$ & 0,01 & 3,15 & 2,7 & $0,8-1,2$ \\
\hline Valina & 1,38 & 0,04 & 5,87 & 5,4 & 1,0 \\
\hline Metionina + Cistina & $0,64^{*}$ & 0,04 & 2,11 & 2,7 & 1,3 \\
\hline Isoleucina & 1,20 & 0,03 & 4,87 & 4,7 & 1,0 \\
\hline Leucina & 1,71 & 0,03 & 7,80 & 6,7 & 1,4 \\
\hline Fenilalanina + Tirosina & 1,9 & 0,03 & 8,53 & 7,4 & 1,4 \\
\hline Lisina & 1,75 & 0,03 & 9,54 & 9,0 & 1,2 \\
\hline
\end{tabular}

O aminoácido essencial triptofano não foi quantificado por ser destruído pela hidrólise ácida realizada na análise.

* aminoácidos limitantes ao padrão de referência FAOMHO (1985); a as análises foram realizadas em duplicata; M: média; DP: desvio-padrão.

Tabela 3. Análise sensorial do pão de queijo enriquecido com levedura autolisada proveniente de cachaça de alambique. Belo Horizonte (MG), 2009.

\begin{tabular}{|c|c|c|c|c|c|}
\hline Análise sensorial & Aparência & Cor & Aroma & Textura & Sabor \\
\hline Gostei extremamente & 5,6 & 2,8 & 19,7 & 35,2 & 50,7 \\
\hline Gostei muito & 7,0 & 11,3 & 42,3 & 38,0 & 28,2 \\
\hline Gostei moderadamente & 18,5 & 14,1 & 9,9 & 11,3 & 15,5 \\
\hline Gostei ligeiramente & 7,0 & 5,6 & 4,2 & 9,9 & 4,2 \\
\hline Não gostei nem desgostei & 12,7 & 16,9 & 14,1 & 2,8 & 1,4 \\
\hline Desgostei ligeiramente & 25,3 & 19,7 & 4,2 & 1,4 & 0 \\
\hline Desgostei moderadamente & 12,7 & 12,7 & 5,6 & 0 & 0 \\
\hline Desgostei muito & 4,2 & 14,1 & 0 & 1,4 & 0 \\
\hline Desgostei extremamente & 7,0 & 2,8 & 0 & 0 & 0 \\
\hline
\end{tabular}

Nota-se que o conteúdo de alguns aminoácidos essenciais, considerados limitantes da qualidade proteica, encontra-se abaixo do recomendado pela Organización Mundial de la Salud ${ }^{19}$, quais sejam histidina e metionina + cistina.

Os resultados das análises microbiológicas do autolisado de levedura desidratado mostraram que o valor obtido para Salmonella sp. $/ 25 \mathrm{~g}$ foi ausência em $25 \mathrm{~g}$; para Coliformes a $45^{\circ} \mathrm{C} / \mathrm{g}$ foi menor que 3,0 NMP/g; para Estafilococos coagulase positiva/g foi menor que $10 \mathrm{UFC/g}$; e para Bacilus cereus/g foi menor que $10 \mathrm{UFC/g}$.

A Tabela 3 mostra a distribuição percentual do julgamento dos participantes quanto aos atributos aparência, cor, aroma, textura e sabor do pão de queijo enriquecido com levedura autolisada. Para as características aparência e cor, o maior percentual observado foi para "desgostei ligeiramente" (25,3\% e 19,7\%, respectivamente); para aroma e textura, o maior percentual foi de "gostei muito" $(42,2 \%$ e 38,0\%, respectivamente); e, para o sabor do pão de queijo, o maior percentual observado foi de "gostei extremamente" (50,7\%).

A Tabela 4 apresenta o percentual de participantes que aceitaram, que não gostaram nem desgostaram, e que rejeitaram as características do pão de queijo. Observou-se que os maiores índices de rejeição deram-se em relação às características aparência e cor (49,3\% para ambas), sugerindo que a coloração escura do produto teria influenciado a rejeição. Por outro lado, o maior percentual de julgadores aceitou as características aroma, textura e sabor. Para a característica aro- 
Tabela 4. Porcentagem de aceitação, de não gostar nem desgostar, e de rejeição ao pão de queijo enriquecido com levedura autolisada de alambique. Belo Horizonte (MG), 2009.

\begin{tabular}{lccc}
\hline Característica & Aceitação (\%) & Não gostar nem desgostar (\%) & Rejeição (\%) \\
\hline Aparência & 38,0 & 12,7 & 49,3 \\
Cor & 33,8 & 16,9 & 49,3 \\
Aroma & 76,1 & 14,1 & 9,9 \\
Textura & 94,4 & 2,8 & 2,8 \\
Sabor & 98,6 & 1,4 & 0,0 \\
\hline
\end{tabular}

ma, obteve-se aceitação de 76,1\%, enquanto apenas 9,9\% rejeitaram essa característica. A textura obteve alto índice de aceitação (94,4\%), enquanto apenas 2,8\% dos participantes rejeitaram essa característica. A característica sabor apresentou maior índice de aceitação (98,6\%) pelos participantes, não tendo ela sido rejeitada por nenhum julgador.

Para a intenção de compra do pão de queijo adicionado do autolisado de levedura, $25,4 \%$ responderam que "compraria isto sempre que tivesse oportunidade"; 12,7\% responderam que "compraria isto muito frequentemente"; $19,7 \%$ responderam que "compraria isto frequentemente" ; 25,4\% disseram que "gosta disto e compraria de vez em quando"; 14,1\% disseram que "compraria isto se estivesse acessível, mas não me esforçaria"; 1,4\% disseram que "raramente compraria isto" e 1,4\% responderam que "só compraria isto se não pudesse escolher outro alimento".

\section{DISCUSS Ã O}

Pela Tabela 1, que mostra a composição centesimal do autolisado de levedura proveniente de cachaça de alambique desidratada em secador de bandeja a $70^{\circ} \mathrm{C}$, observa-se que o teor de proteína encontrado foi de $24,7 \%$, valor inferior ao indicado na literatura para a levedura de destilaria de álcool etílico e para cervejaria, que apresentou o maior teor proteico ${ }^{9,20}$.

A levedura proveniente de cervejaria mostra quantidade de proteína maior que a levedura de cachaça de alambique e de destilaria de álcool etílico. Alguns autores mostraram conteúdo de proteína para o autolisado de aproximadamente 45\% seca em spray dryer ${ }^{11,20}$.

Para proteína proveniente de destilaria de álcool etílico, Santucci et al. ${ }^{17}$ encontraram valor de 38,4\%, e Steckelberg ${ }^{21}$, analisando 21 cepas distintas (Saccharomyces sp.), encontrou valores que variaram entre 39,3\% e 49,2\%. Hisano et al. ${ }^{22}$ obtiveram quantidade de proteína de 34,4\% para o autolisado de levedura desidratada em spray dryer. Já Faria et al. ${ }^{23}$ encontram teor de proteína de 30,4\% desidratada em rolo rotativo e 29,3\% desidratada por spray dryer. Outros valores reportados para levedura de destilaria foram de 28,7\% para safra de 1985, e, para a safra seguinte, de $27,0 \%$, mostrando que vários fatores interferiram na composição centesimal em safras distintas ${ }^{24}$. Dentre esses fatores estão: substrato utilizado, espécie de levedura, método de fermentação, idade das células e condições de secagem. Além disso, o processo de lavagem da biomassa para eliminação das impurezas do leite de levedura pode influenciar na composição das leveduras ${ }^{24}$. Além desses fatores, o menor teor proteico encontrado na levedura descartada da fermentação alcoólica pode ser devido ao método de secagem utilizado ou ao mau uso do secador ${ }^{25}$.

Para aumentar o conteúdo de proteína, após a lavagem, o leite de levedura pode ser submetido à temperatura de $45^{\circ} \mathrm{C}$ a $50^{\circ} \mathrm{C}$, visando à exaustão das reservas de carboidratos acumuladas nas células, os quais se transformarão em álcool, aumentando o teor proteico da levedura ${ }^{26}$.

O conteúdo de lipídeos encontrado na levedura de cachaça de alambique foi de 1,2\% para 
célula autolisada, valor próximo ao descrito na literatura para levedura de destilaria de álcool etílico ${ }^{9,10,17}$, e inferior à levedura proveniente de cervejaria'11,20,27,28.

A quantidade de fibra bruta encontrada na levedura de cachaça de alambique foi de $51,3 \%$, sendo $48,9 \%$ de fibra insolúvel, e $2,4 \%$ de fibra solúvel. Esse resultado contrasta com os dados da literatura para leveduras de cervejaria e de destilaria de álcool etílico, as quais apresentam maior quantidade de fibra solúvel 10,11,17,23.

A composição de polissacarídeos da parede celular das leveduras pode variar em razão de muitos fatores, como linhagem, condições de cultivo e idade da cultura29.

O aumento na ingestão de fibras pode promover efeitos fisiológicos benéficos ao organismo, que incluem a regularização do trânsito intestinal, o controle glicêmico, a redução de câncer de cólon e diverticulite e, ainda, a redução do colesterol sérico ${ }^{30}$. Assim, o alto teor de fibras encontrado caracteriza o autolisado desidrato como boa fonte dessa substância.

A quantidade de cinzas encontrada para o autolisado da levedura de cachaça de alambique foi semelhante à encontrada para autolisado da levedura de destilaria de álcool etílico ${ }^{9,10,17}$, enquanto a levedura de cervejaria ${ }^{11,20}$ mostrou conteúdo de cinzas superior.

Em relação ao perfil de aminoácidos, o valor encontrado para a levedura de cachaça de alambique foi bem inferior aos encontrados na literatura para levedura de cervejaria e de destilaria. Além disso, alguns aminoácidos da levedura da cachaça de alambique mostraram valor abaixo do recomendado pela FAONHO (1985) para adultos $s^{9,11,17,22,27}$. O baixo perfil aminoacídico, juntamente com o menor teor de proteína encontrado no autolisado de levedura de destilaria de cachaça de alambique, pode ser consequência de fatores anteriormente citados, como substrato, safra, lavagem da biomassa e condições de secagem.

Para a ANVISA ${ }^{15}$, os valores microbiológicos aceitáveis para levedura seca são: ausência de Salmonella sp. em 25g; a contagem de coliformes a $45^{\circ} \mathrm{C} / \mathrm{g}$ deve ser menor que $10 \mathrm{NMP} / \mathrm{g}$; Estafilococos coagulase positiva/g deve ser menor $5 \times 10^{2} \mathrm{UFC} / \mathrm{g}$; e Bacilus cereus/g deve ser menor que $5 \times 10^{2} \mathrm{UFC} / \mathrm{g}$. Os resultados das análises microbiológicas realizadas com o autolisado de levedura de cachaça de alambique indicaram que o produto estava apto para consumo humano.

A análise sensorial do pão de queijo com adição de 7,5\% do autolisado de levedura desidratado mostrou que as características aparência e cor obtiveram maior rejeição dos provadores $(49,3 \%)$, enquanto a característica sabor obteve a maior aceitação $(98,6 \%)$ (Tabela 3).

No trabalho desenvolvido por Santucci et al. ${ }^{17}$ com suplementação de autolisado de levedura em diferentes formulações de macarrão, os resultados mostraram rejeições semelhantes ao presente estudo. Na formulação do macarrão com $5,0 \%$ de autolisado de levedura foi observada rejeição de 48,9\% para aparência do produto e de $64,4 \%$ para o atributo cor, enquanto em relação ao sabor o produto obteve uma aprovação de $71,1 \%$. Quando adicionado espinafre juntamente com $7,5 \%$ do autolisado ao macarrão, apenas $22,7 \%$ rejeitaram a aparência e $21,3 \%$ rejeitaram a cor, ao passo que o atributo sabor obteve aceitação de $76,7 \%$. A análise sensorial feita com o macarrão indicou que a rejeição da aparência e da cor, assim como observado com o pão de queijo, deveu-se à cor escura adquirida pela adição da farinha de levedura autolisada. No mercado nacional não é comum encontrar produtos adicionados com levedura, motivo pelo qual os consumidores não estão habituados com a aparência desses alimentos, o que justifica sua maior rejeição pela aparência e pela cor.

Outros autores ${ }^{10}$ observaram que 0 biscoito tipo água e sal, acrescentado de $5 \%$ de autolisado de levedura de destilaria de álcool etílico, obteve maior aceitação que o biscoito padrão. Esse estudo reforça o resultado obtido para a característica sabor do pão de queijo, mostrando que a adição de levedura nos alimentos pode realçar o sabor dos mesmos, aumentando a aceitação. 
No que diz respeito à intenção de compra do produto, uma grande parcela dos participantes respondeu que compraria o produto sempre que tivesse oportunidade e outra contrapôs que gostou do produto e o compraria de vez em quando, o que leva a supor que a primeira parcela compraria motivada pelo aroma, textura e sabor, e que a outra seria desmotivada pela cor e aparência.

\section{O N CLUSÃ O}

A levedura de cachaça de alambique mostrou teor de proteínas satisfatório (acima de 20\%), porém mostrou restrição em relação a sua qualidade nutricional, devido à deficiência dos aminoácidos essenciais histina e metionina + cistina. Mostrou também alto teor de fibra insolúvel e baixo teor de fibra solúvel na sua composição. Essa diferença na composição centesimal e no perfil de aminoácidos da levedura proveniente de cachaça de alambique pode ter sido ocasionada pelo método de fermentação, pela idade das células, pelo método de secagem ou pela safra.

A análise microbiológica mostrou que o autolisado de levedura de cachaça de alambique estava apto para o consumo humano.

A análise sensorial mostrou boa aceitação do pão de queijo adicionado de levedura. Apenas a cor e aparência receberam notas baixas, o que provavelmente ocorreu pelo fato de os consumidores não estarem habituados à cor escura, semelhante a um produto integral. Esse resultado mostrou que o autolisado de levedura de cachaça de alambique pode ser adicionado, com boa aceitação, em alimentos, como por exemplo em pães destinados à merenda escolar, melhorando assim seu perfil nutricional, pois o produto mostrou boa quantidade de proteína e alto teor de fibras. No item intenção de compra, boa parte dos participantes compraria o produto sempre que tivesse oportunidade, ou seja, se estivesse disponível no mercado, enquanto outra parcela compraria de vez em quando, talvez desmotivada pela aparência escura.
Além disso, a utilização da levedura de cachaça de alambique desidratada para o enriquecimento de produtos alimentícios constitui alternativa promissora para evitar seu descarte no meio ambiente, durante o processo de produção de cachaça.

Trabalhos futuros com a levedura proveniente de cachaça de alambique poderão apontar as causas da diferença na composição centesimal com as leveduras de cervejaria e de destilaria de álcool etílico e também sugerir a adição das frações em outros produtos cuja aparência fique mais atrativa.

\section{A GRADECIMENTO}

A Fundação de Amparo a Pesquisa do Estado de Minas Gerais pelo apoio financeiro.

\section{COLABORADORES}

Todos os autores participaram de todas as fases do artigo.

\section{REFERÊ NCIAS}

1. Oliveira ES, Rosa CA, Morgano MA, Serra GE. Fermentation characteristics as criteria for selection of cachaça yeast. World J Microb Biot [Internet]. 2004 [cited 2009 Aug 27]; 20:19-24. Available from: <http://www.springerlink.com/content/l6083n4 v25v8g872/fulltext.pdf>.

2. Costa LF. Leveduras na nutrição animal. Rev Eletrôn Nutritime [Internet]. 2004 [acesso 2009 jun 2]; 1(1):1-6. Disponível em: <http://www.nutritime. com.br/arquivos_internos/artigos/001V1N1PO 1_06_JUL2004.pdf>.

3. Instituto Brasileiro da Cachaça. Dados de Mercado. 2008 [acesso 2010 abril 5]. Disponível em: <http:// www.ibraccachacas.org/index.php? option= com_content\&view=article\&id=47\&ltemid=44>.

4. Oliveira CR, Garíglio HAA, Ribeiro MM, Alvarenga MSP, Maia FX. Cachaça de alambique: manual de boas práticas ambientais e de produção. Convênio de cooperação técnica SEAPA/SEMAD/ AMPAQ/FEAM/IMA [Internet]. Belo Horizonte; 2005 [acesso 2009 ago 27]. Disponível em: <http:// www.feam.br/images/stories/arquivos/Manual_ de_Cachaca_040805.pdf>. 
5. Oliveira EL, Andrade LAB, Faria MA, Evangelista AWP, Morais AR. Uso de vinhaça de alambique e nitrogênio em cana-de-açúcar irrigada e não irrigada. Pesq Agropec Bras [Internet]. 2009 [acesso 2010 jan 21]; 44(11):1398-403. Disponível em: <http://webnotes.sct.embrapa.br/pdf/pab2009/11/ 44n11a05.pdf>

6. Minas Gerais. Imprensa Oficial. Cresce exportação da cachaça mineira [Internet]. 2009 [acesso 2010 abr 5]. Disponível em: <http://www2.iof.mg.gov.br/ index.php?/Destaque-Arquivo/Cresce-exportacaoda-cachaca-mineira.html>.

7. Soares PA, Rossell CEV. O setor sucroalcooleiro e o domínio tecnológico [Internet]. São Paulo: USP; 2007 [acesso 2008 dez 12]. Disponível em: <http:// www.naippe.fm.usp.br/trabalhos/vol2.PDF>.

8. Watanabe, AL. Suplementação de levedura desidratada (Saccharomyces cerevisiae) e derivados na alimentação de juvenis de pacu (Piaractus mesopotamicus) [dissertação]. Pirassununga: Universidade de São Paulo; 2006 [acesso 2008 dez. 12]. Disponível em: <http://www.teses.usp.br/ teses/disponiveis/74/74131/tde-28112006-093 820/pt-br.php>.

9. Yamada EA, Alvim ID, Santucci MCC, Sgarbieri VC. Composição centesimal e valor protéico de levedura residual da fermentação etanólica e de seus derivados. Rev Nutr. 2003; 16(4):423-32. doi: 10.1590/S1415-52732003000400006.

10. Santucci MCC, Alvim ID, Faria EV, Sgarbieri VC. Efeito do enriquecimento de biscoitos tipo água e sal, com extrato de levedura (Saccharomyces sp.). Ciênc Tecnol Aliment [Internet]. 2000 [acesso 2008 dez 12]; 23(3):441-46. Disponível em: <http:// www.scielo.br/scielo.php?script=sci_arttext\& pid $=S 0101-0612003000300025>$.

11. Sgarbieri VC, Alvim DA, Vilela ES, Baldini VLS, Bragagnolo N. Produção piloto de derivados de levedura (saccharomyces cerevisiae) para uso como ingrediente na formulação de alimentos. Braz J Food Technol. 1999; 2(1,2):119-25.

12. Chaud SG. Fracionamento e caracterização química da parede celular de levedura: propriedades funcionais e fisiológicas das frações [tese]. Campinas: Universidade Estadual de Campinas; 2004 [acesso 2008 dez 12]. Disponível em: <http://www. fea.unicamp.br/alimentarium/ver_documento. php?did=281\&pid=2\&p=4\&order=titulo $>$.

13. Instituto Adolfo Lutz. Procedimentos e determinações gerais. In: Métodos químicos e físicos para análise de alimentos [Internet]. São Paulo: Instituto Adolfo Lutz; 2008. Capitulo 4. [acesso 2007 ago 17]. Disponível em: <http://www.ial.sp.gov.br/ index.php?option $=$ com_remository\&ltemid $=07 \&$ func $=$ select \&orderby $=1 \& \mid$ temid $=7>$.
14. Association of Official Analytical Chemists. Official methods of analysis of AOAC International. $17^{\text {th }}$ ed. Gaithersburg: AOAC; 2000. v.2.

15. Brasil. Agência Nacional de Vigilância Sanitária. Resolução n. 12, de 2 de janeiro de 2001. Regulamento técnico sobre os padrões microbiológicos para alimentos. Diário Oficial da União [Internet]. 2001 [acesso 2007 ago 5];10 jan. Disponível em: $<$ http://www.anvisa.gov.br/legis/resol/12_01rdc. htm>.

16. Brasil. Ministério da Agricultura, Pecuária e Abastecimento. Instrução Normativa $n^{\circ} 62$, de 26 de agosto de 2003. Oficializar os métodos analíticos oficiais para análises microbiológicas para controle de produtos de origem animal e água. Brasília (DF); 2003. Diário Oficial da União. 200318 set.

17. Santucci MCC, Alvim ID, Schimit F, Faria EV, Sgarbieri VC. Enriquecimento de macarrão tipo tubo (massa curta) com derivados de levedura (saccharomyces sp.): impacto nutricional e sensorial. Ciênc Tecnol Aliment. 2003; 23(2):290-95.

18. Stone H, Sidel JL, Olivers S, Woolsey A, Singleton C. Sensory evaluation by quantitative descriptive analysis. Food Technology.1998; 52(2):48-52.

19. Organización Mundial de la Salud. Necesidades de energiá y de proteínas. Ginebra: OMS; 1985. Series de Informes Técnicos, 724.

20. Vilela ESD, Sgarbieri VC, Alvim ID. Valor nutritivo da biomassa de células íntegras, do autolisado e do extrato de levedura originária de cervejaria. Rev Nutr. 2000; 13 (2):127-34. doi: 10.15 90/\$1415-5 2732000000200007.

21. Steckelberg C. Caracterização de leveduras de processos de fermentação alcoólica utilizando atributos de composição celular e características cinéticas [tese]. Campinas: Universidade Estadual de Campinas; 2001 [acesso 2008 ago 5]. Disponível em: <http://cutter.unicamp.br/document/?code $=v t \mid s 000232430 \& f d=y>$.

22. Hisano H, Sampaio FG, Barros MM, Pezzato LE. Composição nutricional e digestibilidade aparente da levedura íntegra, da levedura autolisada e da parede celular pela tilápia-do-Nilo. Ciên An Bras [Internet]. 2008 [acesso 2008 ago 5]; 9(1):43-9. Disponível em: <http://www.revistas.ufg.br/index. php/vet/article/viewFile/3658/3424>.

23. Faria HG; Scapinello C, Furlan AC, Moreira I, Martins EM. Valor nutritivo das leveduras de recuperação (Saccharomyces sp.), seca por rolo rotativo ou por "Spray-Dry", para coelhos em crescimento. Rev Bras Zootec [Internet]. 2000 [acesso 2008 ago 5]; 29(6):1750-3. Disponível em: <http://www. scielo.br/scielo. php?pid=\$1516-359820000006 00022\&script=sci_arttext $>$. 
24. Filho DL, Ghiraldini JA, Rossell CEV. Estudos de otimização da recuperação de biomassa de levedura em destilarias. Anais do Workshop sobre a produção de biomassa de levedura: utilização em alimentação humana e animal. Campinas: Instituto de Tecnologia de Alimentos; 1996. p.59-67.

25. Lima UA, Sato S. Proteína de origem microbiana. In: Biotecnologia industrial: biotecnologia na produção de alimentos. São Paulo: Editora Edgard Blucher; 2001. v. 4:421-45.

26. Blumer SLG. Enriquecimento com ferro em levedura (Saccharomyces cerevisiae) [dissertação]. Piracicaba: Universidade de São Paulo; 2002 [acesso 2008 ago 5]. Disponível em: <http://www.teses. usp.br/teses/disponiveis/11/11141/tde-21112002161816/pt-br.php>.

27. Pádua DMC, Urbinati EC, Carneiro DJ, Pádua JT, Silva PC. Determinação da composição em aminoácidos das proteínas da levedura de álcool (saccharomyces cerevisiae) seca, e da farinha de peixe como ingredientes para rações de peixes de água doce. An Esc Agron e Vet [Internet]. 1997 [acesso 2009 ago 27]; 27(2): 85-97. Disponível em: <http://www.revistas.ufg.br/index.php/pat/article/ view/2973/3019>.

28. Caballero-Córdoba GM, Pacheco MTB, Sgarbieri VC. Composição química da biomassa de levedura integral (Saccharomyces sp.) e determinação do valor nutritivo da proteína em células integras ou rompidas mecanicamente. Ciênc Tecnol Aliment. 1997; 17(2):102-6.

29. Assis EM. Componentes da parede celular de leveduras: proteínas e polissacarídeos de interesse das indústrias farmacêuticas e de alimentos. Proceedings of the Workshop sobre produção de biomassa de levedura: utilização em alimentação humana e animal. Campinas: Ital; 1996. p.41-51.

30. Weickert MO, Pfeiffer AFH. Metabolic effects of dietary fiber consumption and prevention of diabetes. J Nutr [Internet]. 2008 [cited 2009 Aug 27]; 138:439-42. Available from: <http://jn. nutrition.org/cgi/reprint/138/3/439>.

Recebido em: 29/10/2009

Versão final reapresentada em: 28/10/2010

Aprovado em: 8/11/2010 
484 | G.R.V. RAMOS et al.

ANEXO

ANÁLISE SENSORIAL DO PÃO DE QUEIJO COM AUTOLISADO DE LEVEDURA

Por favor, dê sua opinião sobre as seguintes características da amostra, na escala abaixo a opção que melhor reflita seu julgamento:

\begin{tabular}{|c|c|c|c|c|c|}
\hline & Aparência & Cor & Aroma & Textura & Sabor \\
\hline Gostei extremamente & () & () & $($ ) & () & $($ ) \\
\hline Gostei muito & () & () & () & () & () \\
\hline Gostei moderadamente & $($ ) & () & $($ ) & ( ) & $($ ) \\
\hline Gostei ligeiramente & $(\quad)$ & $($ ) & () & () & () \\
\hline Indiferente & () & () & () & () & () \\
\hline Desgostei ligeiramente & () & () & $($ ) & $($ ) & ( ) \\
\hline Desgostei moderadamente & () & $($ ) & ( ) & ( ) & () \\
\hline Desgostei muito & $(\quad)$ & () & $(\quad)$ & () & $(\quad)$ \\
\hline Desgostei extremamente & $($ ) & $($ ) & $($ ) & ( ) & $($ ) \\
\hline
\end{tabular}

( ) Compraria isto sempre que tivesse oportunidade

( ) Compraria isto muito frequentemente

( ) Compraria isto frequentemente

( ) Gosto disto e compraria de vez em quando

( ) Compraria isto se estivesse acessível, mas não me esforçaria

( ) Não gosto disto, mas compraria ocasionalmente

( ) Raramente compraria isto

( ) Só compraria isto se não pudesse escolher outro alimento

( ) Só compraria isto se fosse forçado (a) 